\title{
Properties enhancement of oil palm plywood through veneer pretreatment with low molecular weight phenol-formaldehyde resin
}

\begin{abstract}
One of the problems dealing with oil palm stem (OPS) plywood is the high veneer surface roughness that results in high resin consumption during the plywood manufacturing. In this study, evaluation was done on the effects of pretreatment of OPS veneers with phenolformaldehyde resin on the bond integrity and bending strength of OPS plywood. OPS veneers were soaked in low molecular weight phenol-formaldehyde resin (LMW PF) for 20 seconds to obtain certain percentage of resin weight gain. OPS plywoods were produced using two types of lay-ups (100\% outer veneer type and $100 \%$ inner veneer type) and two ureaformaldehyde (UF) adhesive spread amounts $(200 \mathrm{~g} / \mathrm{m} 2$ and $250 \mathrm{~g} / \mathrm{m} 2)$. The results show that pretreating the veneer with LMW PF could reduce the penetration of the adhesive into the fibres during gluing step. UF adhesive spread amount of $200 \mathrm{~g} / \mathrm{m} 2$ is sufficient to produce good quality OPS plywood. The technique used in this study was able to enhance the mechanical properties of OPS plywood as well as reduce the amount of resin consumption.
\end{abstract}

Keyword: Oil palm stem plywood; Low molecular weight phenol-formaldehyde resin; Mechanical properties; Bond integrity 